\title{
Analisis Efektifitas Mesin/Alat Pabrik Gula Menggunakan Metode Overall Equipments Effectiveness
}

\author{
Subiyanto $^{1 *}$
}

\begin{abstract}
The national sugar production capability especially of the state owned sugar factory tends to decrease while demand increases. To overcome the problem, government has issued the presidential Decree No. 5/2010 and declared a revitalization program of sugar industry as a priority development program. The Ministry of Industry has implemented the program by restructuring the sugar factory's machinery/equipments. Since there are many of factories (51 units) and the budget is limited, the ministry should be selective as to which factories need to be restructered, and therefore the program shoud be supported by prior information about the machinery efficiency status of each factory. To provide those information, this study applies the application of the Overall Equipment Effectiveness (OEE) method on 39 state owned sugar factories. The results indicate that the everage rate of OEE for the 39 sugar factories for the year of 2010 to 2012 is $61.28 \%$ (best practice: 77.4\%), while Availability, Performance, and Quality is $86.43 \%, 91.39 \%$, and $77.02 \%$ respectively. The study also identifies 19 worst factories in efficiency, and therefore recommends those factories as priority to be restructured.
\end{abstract}

Keywords: Overall Equipment Effectiveness (OEE), revitalization of sugar industry, state owned sugar factory.

\section{Pendahuluan}

Gula merupakan komoditas yang mempunyai nilai strategis bagi ketahanan pangan dan peningkatan pertumbuhan perekonomian masyarakat Indonesia. Di lain pihak, produksi gula nasional saat ini tidak mencukupi kebutuhan dalam negeri, baik untuk konsumsi rumah tangga maupun industri. Pada tahun 2008, produksi sebesar 2,74 juta ton, sementara konsumsi mencapai 3,58 juta ton (Sewoko [1]). Pada tahun 2013, produksi mencapai 2,5 juta ton, sementara kebutuhannya mencapai 5,8 juta ton (Ketua Forum Perkembangan Perkebunan Strategi Berkelanjutan dalam Harian Neraca [2]).

Menyikapi kondisi tersebut, pemerintah mengeluarkan Kepres nomor 57 tahun 2004 [3], dan menetapkan gula sebagai barang dalam pengawasan. Implikasi dari kebijakan ini adalah bahwa pemerintah harus menjamin ketersediaan dan menjaga harga gula nasional. Ini berarti pemerintah perlu memperhatikan upaya peningkatan kemampuan produksi gula dalam negeri dan kondisi tercukupinya gula untuk konsumsi dalam negeri. Dalam upaya peningkatan kemampuan produksi dalam negeri, Peraturan Presiden No. 5 Tahun 2010 tentang Rencana Pembangunan Jangka Menengah Nasional (RPJMN) 2010-2014 [4] telah mencantumkan Program Revitalisasi Industri Gula sebagai salah satu prioritas

\footnotetext{
1 Pusat Audit Teknologi, Badan Pengkajian dan Penerapan Teknologi. Л. Raya Puspiptek - Serpong, Tangerang Selatan 15311, Indonesia. Email: biyan_to2003@yahoo.com

*Penulis korespondensi
}

pembangunan, dengan target Swasembada Gula pada tahun 2014. Sementara itu untuk mencukupi persediaan gula dalam negeri, pemerintah telah mengeluarkan kebijakan importasi yang diatur melalui Keputusan Menteri Perindustrian dan Perdagangan Nomor 527/MPP/Kep/9/2004 tentang Ketentuan Impor Gula sebagaimana telah diubah beberapa kali terakhir dengan Peraturan Menteri Perdagangan Nomor 18/M-DAG/PER/4/ 2007 [5].

Urgensi program revitalisasi industri gula didasarkan kepada kenyataan menurunnya kinerja produksi gula nasional (sebagaimana ditunjukkan pada Tabel 1), sementara permintaan semakin meningkat sejalan dengan pertambahan penduduk, daya beli masyarakat, serta jumlah industri pengguna gula (industri makanan, minuman, dan farmasi).

Produksi gula kristal putih (GKP) yang menjadi sasaran akhir dari Program Revitalisasi Industri Gula ternyata kinerjanya selama periode 2008-2012 justru menurun dengan rata-rata pertumbuhan sebesar $-0,47 \%$. Hal ini terjadi karena laju peningkatan luas tanaman tebu (1,39\%) dan peningkatan rendemen $(0,57 \%)$ tidak sebanding dengan laju penurunan produktivitas tebu (-3,26\%). Sasaran Program Revitalisasi Industri Gula ke arah swasembada gula agar volume impor gula berkurang, ternyata juga masih belum sesuai harapan, karena volume impor pada periode 2008-2012 naik dengan rata-rata sebesar 4,6\%. Kontribusi pabrik gula (PG) BUMN terhadap produksi GKP nasional juga masih rendah (sekitar 60\%), walaupun 52 unit dari $62 \mathrm{PG}$ nasional (84\%) berstatus BUMN. Ini mengindi- 
Tabel 1. Parameter kinerja industri gula tahun 2008-2012

\begin{tabular}{lrrrrrr}
\hline Parameter Kinerja Industri & \multicolumn{1}{c}{2008} & \multicolumn{1}{c}{2009} & \multicolumn{1}{c}{2010} & \multicolumn{1}{c}{2011} & \multicolumn{1}{c}{2012} & \multicolumn{1}{c}{ Growth (\%) } \\
\hline Luas Tanam (Ha) $^{\mathrm{a}}$ & 436,505 & 441.440 & 454.111 & 451.788 & 461.082 & 1,39 \\
Produktivitas (ton GKP/ha) $^{\mathrm{a}}$ & 6.11 & 5,95 & 5,29 & 5,03 & 5,31 & $-3,26$ \\
Rendemen (\%) $^{\mathrm{d}}$ & 8.0 & 7,6 & 7,0 & 7,4 & 8,1 & 0,57 \\
Produksi GKP (juta ton) $^{\mathrm{a}}$ & 2.668 & 2,517 & 2,29 & 2,268 & 2,580 & $-0,47$ \\
Share Prod GKP BUMN (\%) $^{\mathrm{b}}$ & - & 55,0 & 61,5 & 61,0 & 57,0 & 1,48 \\
Impor GKP (juta ton)c $^{\mathrm{c}}$ & 1.152 & 1,66 & 2,022 & 2,717 & 0,494 & 4,61 \\
Harga Rata-rata (Rp/kg) $^{\mathrm{c}}$ & 6,191 & 8.205 & 10.509 & 9.981 & 11.494 & 17,69 \\
\hline
\end{tabular}

Sumber:

a Ditjen Perkebunan Kementerian Pertanian [6];

b Kementerian BUMN [7];

c KPB PTP Nusantara (dalam Pusat Data dan Sistem Informasi Pertanian [8]);

d Sewoko [1]; Kementerian BUMN [7]; Ditjen Perkebunan Kementerian Pertanian [6];

kasikan rendahnya produktivitas $\mathrm{PG}$ di lingkungan BUMN. Ini dapat dipahami, karena permesinan di PG BUMN rata-rata umurnya sudah tua, sehingga dipandang relevan untuk direvitalisasi.

Untuk percepatan pelaksanaan Program Revitalisasi Industri Gula, Pemerintah menerbitkan Inpres nomor 1 tahun 2010, dengan menugaskan Kementerian Perindustrian sebagai penanggungjawab program. Penugasan ini ditindaklanjuti oleh Kementerian Perindustrian dengan membuat kebijakan Restrukturisasi Mesin/Peralatan Pabrik Gula yang ditetapkan melalui Permenperin No: 91/M-IND/ PER/11/2008 yang telah diubah dua kali terakhir pada Permenperin No: 86/M-IND/PER/10/2011. Fokus restrukturisasi adalah peremajaan mesin/ peralatan pabrik eksisting di lingkungan BUMN. Kegiatan utamanya adalah memberikan bantuan keringanan dan bantuan langsung mesin/peralatan yang diperlukan oleh pabrik gula BUMN dengan tujuan untuk meningkatkan kapasitas giling, efisiensi pabrik gula, dan kualitas produk gula kristal putih (Kementerian Perindustrian [9]).

Permasalahannya, dengan jumlah PG BUMN sebanyak 51 unit yang rata-rata umur mesinnya sudah tua, maka investasi yang diperlukan untuk melakukan restrukturisasi akan sangat besar. Dilain pihak, dana yang disediakan pemerintah terbatas. Pemerintah perlu membuat prioritas dengan mengalokasikan dana kepada pabrik gula yang memang sangat memerlukan. Tentunya untuk melakukan ini pemerintah memerlukan informasi awal tentang kondisi peralatan pabrik gula agar sasaran restrukturisasi berjalan efektif. Di lain pihak, karena program restrukturisasi mesin/alat dilaksanakan secara multiyears (mulai tahun 2010), maka perlu juga evaluasi apakah program yang telah dilakukan efektif, dalam arti mampu memperbaiki efektifitas dan efisiensi mesin/alat PG. Salah satu tool yang telah banyak digunakan untuk mengukur tingkat efektifitas dan efisiensi dari peralatan keseluruhan pabrik khususnya pada industri manufaktur, adalah Overall Equipment Effectiveness (OEE). Penggunaan metode OEE dalam studi ini dimaksudkan untuk membantu pemerintah dalam menentukan daftar PG yang perlu mendapat prioritas program revitalisasi.

\section{Pengertian dan Manfaat OEE}

Nakajima [10] mendefinisikan OEE sebagai metrik atau ukuran untuk mengevaluasi efektivitas peralatan. OEE berupaya untuk mengidentifikasi kehilangan produksi dan kehilangan biaya lain yang tidak langsung dan tersembunyi, yang memiliki kontribusi besar terhadap biaya total produksi. Kehilangan/kerugian ini dirumuskan Huang et al. [11] sebagai fungsi dari sejumlah komponen eksklusif yang berhubungan, yakni: Ketersediaan (Availability), Kinerja (Performance) dan Kualitas (Quality). Williamson [12] menjelaskan keandalan OEE dengan kemampuannya mengukur efektivitas secara total (complete, inclusive, whole) dari kinerja suatu peralatan dalam melakukan suatu pekerjaan yang sudah direncanakan, dan diukur dari data aktual terkait dengan availability, performance efficiency, dan quality of product. Informasi dari OEE digunakan untuk mengidentifikasi dan mengklasifikasikan penyebab dari rendahnya kinerja suatu peralatan.

Sebagaimana didefinisikan pada awalnya oleh Nakajima [10], tujuan OEE adalah untuk mengevaluasi kemajuan dari filosofi Total Productive Maintenance (TPM) melalui pengukuran peralatan individu. Total Productive Maintenance (TPM) adalah suatu prinsip manajemen untuk meningkatkan produktivitas dan efisiensi produksi perusahaan dengan menggunakan mesin secara efektif (Robinson dan Ginder [13]). Namun, karena peningkatan penggunaannya dalam industri dan efektivitasnya sebagai ukuran kinerja untuk peralatan per unit, penelitian lebih lanjut berupaya untuk memperluas cakupan aplikasi OEE untuk seluruh proses atau pabrik. Sebagai contoh, laporan hasil penelitian Sherwin [14] mengusulkan proses keefektifan untuk mengukur kinerja proses secara keseluruhan, 
kemudian Nachiappan dan Anantharam [15] serta Braglia et al. [16] menyajikan efektifitas keseluruhan peralatan dari suatu lini manufaktur untuk menilai kinerja lini produksi, sementara Oechsner et al. [17] mengusulkan keefektifan keseluruhan untuk mengukur kinerja dari seluruh pabrik.

Penggunaan metode OEE untuk evaluasi efektivitas mesin/alat di dalam negeri sudah dilakukan oleh beberapa peneliti, tetapi masih terbatas untuk mesin/alat individu. Di antaranya adalah Rahmad, et al. [18] dengan obyek penelitian mesin gilingan I di salah satu pabrik gula, kemudian Mulyati [19] dengan obyek penelitian alat fuel scraper conveyor di pabrik kelapa sawit, serta Fitriadi dan Kuncoro [20] dengan obyek mesin $C N C M A-1$ di salah satu pabrik rokok. Evaluasi efisienasi mesin/alat di pabrik gula juga sudah dilakukan oleh manajemen internal secara reguler, tetapi menggunakan parameter yang bersifat parsial (per alat atau per stasiun). Pengukuran efisiensi alat secara menyeluruh di pabrik gula dilakukan menggunakan metode overall recovery yang dikembangkan Intertional Society of Sugar Cane Technologist (PTPN X [21]), tetapi metode ini dipandang kurang lengkap karena hanya menekankan kepada process losses. Studi ini bermaksud menggunakan OEE sebagai alat ukur untuk mengevaluasi efisiensi seluruh alat di pabrik gula BUMN, dan hasilnya digunakan sebagai bahan analisis untuk mengevaluasi efektifitas program aksi restrukturisasi (peremajaan) mesin/alat pada pabrik gula tahun 2010-2012. Pengukuran OEE umumnya digunakan pada tataran mikro untuk tujuan perawatan mesin/alat, sementara pada studi ini OEE diposisikan sebagai pendekatan makro untuk kebijakan prioritas pembinaan pabrik gula nasional khususnya BUMN.

Solusi OEE dapat membantu para produsen mendapatkan status yang diakui oleh dunia. Untuk dapat memanfaatkan metode OEE sebagai sistem ukuran untuk memonitor dan memperbaiki efisiensi proses, suatu perusahaan harus melakukan perancangan sistem ukuran OEE secara spesifik yang dimulai dari identifikasi penyebab kerugian, membuat target capaian setiap faktor OEE dan menentukan skala prioritas dalam mencapai $O E E$ World Class. Nilai OEE World Class adalah sebesar 85\%, dengan komposisi elemen Availability sebesar 90\%, Performance sebesar 95\% dan Quality sebesar 99,9\% (Dal [22]; Wauters dan Mathot [23]).

\section{Metode Penelitian}

\section{Perhitungan Elemen OEE}

Elemen OEE dalam manajemen mesin dan peralatan pabrik secara umum diilustrasikan oleh EXOR/Data Visor Marquees [24] seperti pada
Gambar 1. Terlihat pada Gambar 1 bahwa ketidaksempurnaan tingkat efektifitas mesin/alat pada suatu pabrik dikarenakan adanya berbagai kehilangan (losses), yang berdasarkan penyebabnya Wauters and Mathot [23] mengelompokkannya atas: (1) kehilangan karena mesin yang tidak berfungsi sesuai rencana (malfunction), (2) kehilangan dalam proses, dan (3) kehilangan karena faktor luar (external losses). Lebih jauh dijelaskan bahwa kehilangan karena sebab malfunction dan proses dikategorikan sebagai kehilangan karena faktor teknis (technical losses), sedangkan external losses dapat dikelompokkan lagi penyebabnya yaitu karena direncanakan (planned losses) dan karena tidak direncanakan (unplanned losses). Kehilangan karena direncanakan dapat terjadi karena: (a) modifikasi atau perbaikan mesin/alat (dimasa giling pabrik), (b) kebutuhan tertentu (kuantitas dan kualitas produk) yang berdampak kepada kapasitas dan/atau kecepatan mesin produksi, atau (c) pertimbangan sosial (hari besar, dan lain-lain.) yang berdampak kepada jam kerja pabrik. Kehilangan yang tidak direncanakan terjadi karena: (a) kekurangan tenaga kerja/ operator (biasa terjadi di PG sekitar hari lebaran), (b) kekurangan bahan baku (karena pengelolaan tebang angkut tebu yang kurang baik di PG), (c) faktor lingkungan yang berdampak kepada jam giling pabrik.

Konsep OEE pada umumnya banyak diaplikasikan kepada industri manufaktur, sementara pabrik gula lebih dekat kepada industri proses. Di samping itu, data utama studi ini menggunakan data sekunder khususnya laporan giling pabrik, yang formatnya sudah baku (tidak dipublikasikan). Kondisi ini menuntut penyesuaian pemahaman konsep OEE di pabrik gula dengan kondisi operasional dan format laporan giling yang ada di pabrik gula, sebagaimana disampaikan pada Tabel 2.

Berdasarkan padanan tersebut, selanjutnya perhitungan elemen OEE dilakukan dengan formula sbb.:

$$
\begin{aligned}
& \text { - Availability } \\
& =\frac{\text { Run Time }}{\text { Total Time }} \times 100 \%= \\
& \frac{\text { Jumlah Hari Giling }}{\text { Jumlah Hari Giling }+ \text { Jumlah Hari Berhenti Giling }} \times 100 \% \\
& \text { - Performance }=\frac{\text { Total Count }}{\text { Target Counter }} \times 100 \%= \\
& \frac{\text { Kapasitas Giling Eksklusif }}{\text { Kapasitas Giling Terpasang }} \times 100 \% \\
& \text { - Quality } \\
& =\frac{\text { Good Count }}{\text { Total Count }} \times 100 \%= \\
& \frac{\text { Realisasi Produksi GKP }}{\text { Total Tebu Digiling } \times \text { Pol Tebu }} \times 100 \%= \\
& \text { Overall Recovery } \\
& \text { - Overall Equipments Effectiveness (OEE) } \\
& =\text { Availibility } \times \text { Performance } \times \text { Quality }
\end{aligned}
$$




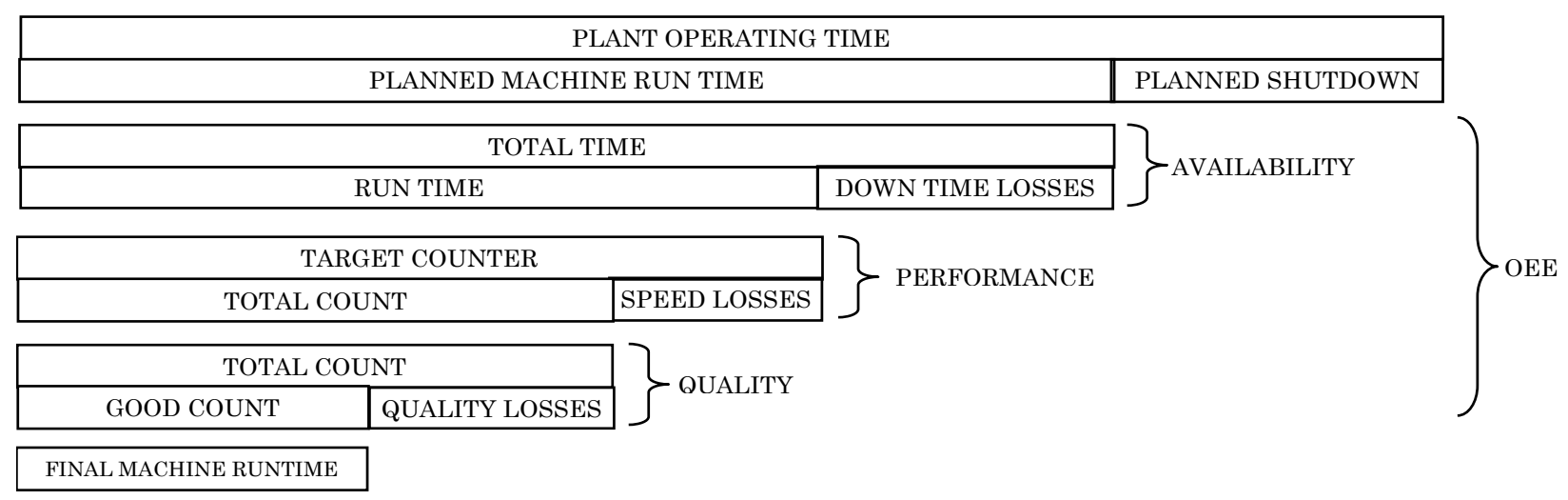

Sumber : EXOR / DataVisor Marquees (200?). The Complete Guide to Simple OEE.

Gambar 1. Skema elemen OEE [24]

Tabel 2. Padanan elemen OEE dengan kondisi operasional dan parameter giling PG

\begin{tabular}{|c|c|c|}
\hline Parameter OEE & Parameter giling PG & Keterangan \\
\hline $\begin{array}{l}\text { Planned machine run } \\
\text { time }=\text { total time }\end{array}$ & $\begin{array}{l}\text { Masa giling atau jumlah hari kampanye } \\
\text { (periode awal - akhir giling) }\end{array}$ & $\begin{array}{l}\text { Ditentukan berdasarkan perhitungan pasokan bahan } \\
\text { baku tebu yang dipengaruhi oleh faktor musim }\end{array}$ \\
\hline Planned shut down & $\begin{array}{l}\text { Masa perawatan/perbaikan besar mesin } \\
\text { pabrik gula (turn around) }\end{array}$ & dilakukan pada waktu di luar masa panen tebu \\
\hline Run time & Jumlah hari giling & \\
\hline Down time losses & $\begin{array}{l}\text { Jumlah hari atau jam berhenti giling (faktor } \\
\text { dalam dan luar pabrik) }\end{array}$ & $\begin{array}{l}\text { Terjadi karena mesin rusak (internal) atau atau } \\
\text { sebab kekurangan bahan baku tebu (eksternal) }\end{array}$ \\
\hline Target counter & Kapasitas Giling Terpasang & $\begin{array}{l}\text { Kemampuan/kecepatan rancangan serangkaian me- } \\
\text { sin pabrik dalam mengolah tebu, dalam ton tebu per } \\
\text { hari (ton cane per day=TCD) }\end{array}$ \\
\hline Total count & Kapasitas Giling Eksklusif (KES) & $\begin{array}{l}\text { Kemampuan/kecepatan pengolahan tebu secara } \\
\text { efektif (TCD) }\end{array}$ \\
\hline Speed losses & - & $\begin{array}{l}\text { Mesin/rangkaian mesin tidak bekerja maksimal } \\
\text { (malfunction) atau karena keterlambatan pasokan } \\
\text { tebu sehingga setting kecepatan giling tidak sesuai } \\
\text { kapasitas terpasang }\end{array}$ \\
\hline Total count & $\begin{array}{l}\text { Jumlah produk Gula Kristal Putih (GKP) } \\
\text { yang seharusnya dihasilkan (potensi) }\end{array}$ & Nilainya $=$ total tebu digiling $\times$ pol tebu ${ }^{1}$ \\
\hline Good count & Realisasi jumlah GKP yang dihasilkan & $\begin{array}{l}\text { Hanya ada satu kualitas produk akhir GKP, dan } \\
\text { dalam hal ini diposisikan sebagai good count }\end{array}$ \\
\hline Quality losses & $\begin{array}{l}\text { Sugar losses (gula yang tidak bisa menjadi } \\
\text { produk akhir GKP) }\end{array}$ & $\begin{array}{l}\text { - Sebagian gula hilang dalam proses, yaitu ikut } \\
\text { dalam ampas, limbah padat (blotong), tetes, dan } \\
\text { berubah menjadi gula reduksi; } \\
\text { - Persen realisasi produk akhir GKP terhadap } \\
\text { potensi produksi disebut dengan Overall Recovery } \\
\text { (OR); } \\
\text { - Sugar losses }=100 \% \text { - OR; }\end{array}$ \\
\hline
\end{tabular}

\section{Pabrik Gula yang Dianalisis}

Pabrik gula BUMN nasional berjumlah 51 unit yang tersebar di 9 perusahaan, yaitu PTPN II, VII, IX, X, XI, XIV, RNI I, RNI II, dan Candi Baru (RNI Group). Perhitungan OEE didasarkan atas data laporan giling dari masing-masing pabrik gula BUMN yang dikompilasi oleh Lembaga Penilai Independen (LPI) Kementerian Perindustrian [25]. Kompilasi data tersebut kemudian diverikasi akurasi dan konsistensinya berdasarkan laporan giling pabrik, dan yang terseleksi digunakan sebagai obyek dalam studi ini. Jumlah PG yang terseleksi sebanyak 39 unit yang tersebar pada 8 perusahaan, sebagaimana ditunjukkan pada Tabel 3.
Tabel 3. Perbandingan jumlah PG BUMN dan obyek studi

\begin{tabular}{llcc}
\hline No & Perusahaan BUMN & $\begin{array}{c}\text { Jumlah PG } \\
\text { (unit) }\end{array}$ & $\begin{array}{c}\text { Obyek Studi } \\
\text { PG (unit) }\end{array}$ \\
\hline 1 & PTPN II & 2 & 2 \\
2 & PTPN VII & 2 & 2 \\
3 & PTPN IX & 8 & 7 \\
4 & PTPN X & 11 & 9 \\
5 & PTPN XI & 16 & 10 \\
6 & PTPN XIV & 3 & 2 \\
7 & RNI I & 3 & 3 \\
8 & RNI II & 5 & 4 \\
9 & Candi Baru/RNI Group & 1 & 0 \\
\hline & JUMLAH & 51 & 39 \\
\hline
\end{tabular}




\section{Hasil dan Pembahasan}

OEE merupakan resultante dari elemen Availability, Performance, dan Quality. Hasil perhitungan ketiga elemen ini menggunakan data laporan 39 pabrik gula BUMN tahun 2010, 2011, dan 2012 memberikan hasil yang secara lengkap ditunjukkan pada Tabel 4.

\section{Availability}

Availability menunjukkan tingkat efektifitas pengoperasian mesin pabrik gula, yang nilainya merupakan persentase antara jumlah hari efektif giling dengan jumlah hari giling yang direncanakan. Besar kecilnya nilai availability mengindikasikan besar kecilnya jumlah hari pabrik berhenti giling (down time), dan juga mengindikasikan kemampuan pabrik dalam melakukan manajemen perawatan mesin/alatnya. Semakin rendah angka availability tentunya akan berpengaruh kepada produktivitas pabrik, karena jumlah tebu yang berhasil digiling semakin terbatas. Best practice availability (kelas dunia) untuk industri manufaktur yang prosesnya bekerja secara kontinu, menurut referensi adalah 90\% (Dal [22]; Wauters dan Mathot [23]). Parameter ini sangat krusial dalam penilaian performa mesin dan alat di pabrik gula BUMN karena umur mesin pabrik yang umumnya sudah tua.

Berdasarkan Tabel 4 dan referensi yang ada dapat disampaikan:

Mengacu kepada best practice availability di industri manufaktur yang nilainya $90 \%$, maka ada 12 (dari 39) atau sekitar $30 \%$ dari PG obyek studi yang ratarata availability-nya selama tiga tahun pengamatan mampu membuat capaian kelas dunia. PG tersebut menyebar di PTPN X (7 PG atau 78\%), PTPN XI (2 PG atau 20\%), dan RNI I (3 PG atau 100\%); Availability rata-rata untuk seluruh $\mathrm{PG}$ dalam obyek studi selama tiga tahun data menunjukkan kecenderungan meningkat, walaupun rata-ratanya masih di bawah best practice, yaitu 86,52\%; Selama tiga tahun data (2010-2012), 10 PG BUMN obyek studi yang rata-rata tingkat availability-nya paling rendah secara berturut-turut (mulai dari yang terrendah) adalah: (1) Bone, (2) Camming, (3) Cinta Manis, (4) Sragi, (5) Bunga Mayang, (6) Jati Barang, (7) Semboro, (8) Tersana Baru, (9) Sei Semayang, dan (10) Kremboong. Rendahnya availability pada PG Bone, Camming, dan Cinta Manis, terjadi karena tingginya jumlah hari berhenti giling yang disebabkan oleh gangguan pasokan tebu (informasi lisan dari mantan Kepala Dinas Teknik PG Camming dan Kepala Dinas Pengolahan PG Cinta Manis). Sementara itu PG dengan availability terbaik umumnya terdapat di PTPN X dan PT RNI I; PG yang tingkat availability-nya selama tiga tahun menurun secara konsisten adalah PG Meritjan (PTPN X) dan PG Redjosarie (PTPN XI). Namun demikian rata-rata availability kedua $\mathrm{PG}$ ini lebih tinggi dari rata-rata PG dalam obyek studi.

\section{Performance}

Performance menunjukkan kecepatan giling efektif dari mesin dan peralatan pabrik relatif terhadap kapasitas terpasang pabrik. Sebagai contoh, kappasitas giling terpasang PG Modjo pada tahun 2012 adalah 3000 ton cane per day (TCD), sementara faktanya pabrik ini hanya beroperasi pada kapasitas giling (eksklusif) 2.496 TCD. Ini berarti ada penurunan kecepatan dari fungsi mesin dan alat, sehingga performance-nya hanya mampu tercapai sebesar 83,2\% (=2.496/3.000). Best practice Performance (kelas dunia) untuk industri manufaktur yang prosesnya bekerja secara kontinyu, menurut referensi adalah 95\% (Dal [22]; Wauters dan Mathot [23]).

Pada tingkatan tertentu, kecepatan giling di pabrik gula terkait dengan kebijakan manajemen dalam menyikapi kondisi peralatan dan target produksi, karena ada trade off antara kecepatan giling dengan losses gula pada stasiun gilingan khususnya gula yang terdapat pada ampas tebu. Jika putaran rol dipercepat, maka kapasitas giling akan bertambah, namun tingkat ekstraksi akan berkurang, karena waktu ampas berada di bawah tekanan rol-rol gilingan menjadi lebih pendek. Sebaliknya, jika menaikkan hasil ekstraksi dengan memperlambat putaran rol dan menambah air imbibisi, atau meninggikan tekanan, maka kapasitas giling akan berkurang. Putaran rol yang terlalu lambat dengan sendirinya akan mengurangi kapasitas giling.

Pengurangan kecepatan giling dapat juga terkait dengan tidak seragamnya kemampuan mesin/alat per stasiun proses. Sebagaimana diketahui bahwa sesuai dengan tahapan proses produksi sejak pemerahan nira tebu sampai terbentuknya gula kristal putih, mesin dan peralatan produksi di pabrik gula dikelompokkan paling tidak ke dalam 8 stasiun, yaitu gilingan, pemurnian, penguapan, masakan, pendinginan, puteran, boiler, dan kelistrikan. Proses terjadi secara semi kontinu, maka kendala kapasitas di satu stasiun akan berdampak kepada stasiun lainnya, yang pada tingkatan tertentu dapat menimbulkan bottleneck. Performance yang rendah menunjukkan bahwa manajemen tidak mampu memanfaatkan potensi mesin/ alat secara maksimal, yang tentunya ini merupakan kerugian. Berdasarkan Tabel 4 dapat disampaikan:

Mengacu kepada best practice Performance (kelas dunia) untuk industri manufaktur yang nilainya 95\%, maka ada 15 (dari 39) atau sekitar 38\% dari 
Tabel 4. Nilai elemen OEE pada 39 PG BUMN Tahun 2010 - 2012

\begin{tabular}{|c|c|c|c|c|c|c|c|c|c|c|c|c|c|}
\hline \multirow{2}{*}{ No } & \multirow{2}{*}{$\begin{array}{l}\text { Perusahaan/ } \\
\text { Pabrik Gula }\end{array}$} & \multicolumn{4}{|c|}{ Availability (\%) } & \multicolumn{4}{|c|}{ Performance (\%) } & \multicolumn{4}{|c|}{ Quality (\%) } \\
\hline & & 2010 & 2011 & 2012 & Rerata & 2010 & 2011 & 2012 & Rerata & 2010 & 2011 & 2012 & Rerata \\
\hline \multicolumn{14}{|c|}{ A PTPN II } \\
\hline 1 & Sei Semayang & $\operatorname{tad}$ & 82,33 & 81,06 & 81,69 & $\operatorname{tad}$ & 90,73 & 87,83 & 89,28 & $\operatorname{tad}$ & 72,46 & 79,77 & 76,12 \\
\hline 2 & Kuala Madu & 90,30 & 81,73 & 85,06 & 85,69 & 89,08 & 88,65 & 92,28 & 90,00 & 83,39 & 80,69 & 85,46 & 83,18 \\
\hline \multicolumn{14}{|c|}{ B PTPN VII } \\
\hline 1 & Bungamayang & 77,43 & 83,83 & 74,03 & 78,43 & 89,74 & 98,45 & 99,07 & 95,75 & 82,11 & 85,88 & 85,59 & 84,53 \\
\hline 2 & Cinta Manis & 73,08 & 82,10 & tad & 77,59 & 92 & 84,97 & tad & 88,49 & 71,9 & 70,03 & $\operatorname{tad}$ & 70,97 \\
\hline \multicolumn{14}{|c|}{ C PTPN IX } \\
\hline 1 & Gondang Baru & 84,36 & 86,50 & 82,51 & 84,46 & 94,59 & 94,09 & 98,42 & 95,70 & 80,99 & 82,17 & 84,86 & 82,67 \\
\hline 2 & Tasikmadu & 88,83 & 90,00 & 83,05 & 87,30 & 95,76 & 96,2 & 96,18 & 96,05 & 84,18 & 83,67 & 85,3 & 84,38 \\
\hline 3 & Modjo & 72,67 & 85,82 & 92,94 & 83,81 & 81,73 & 83,51 & 83,21 & 82,82 & 84,73 & 84,58 & 86,1 & 85,14 \\
\hline 4 & Sragi & 69,14 & 79,32 & 84,42 & 77,63 & 77,9 & 76,71 & 78,52 & 77,71 & 80,06 & 84,16 & 84,59 & 82,94 \\
\hline 5 & Sumberharjo & 86,94 & 75,53 & 87,34 & 83,27 & 97,15 & 95,01 & 91,11 & 94,42 & 82,93 & 83,39 & 83,99 & 83,44 \\
\hline 6 & Pangka & 83,18 & 91,00 & 93,00 & 89,06 & 94,44 & 97,52 & 93,01 & 94,99 & 73,11 & 84,05 & 86,14 & 81,10 \\
\hline 7 & Jati Barang & 67,46 & 81,02 & 86,87 & 78,45 & 90,15 & 90,11 & 90,3 & 90,19 & 80,56 & 81,65 & 84,79 & 82,33 \\
\hline \multicolumn{14}{|c|}{ D PTPNX } \\
\hline 1 & Toelangan &, 31 & 95,73 & 87,49 & 90,85 & 97,22 & 94,95 & 100,8 & 97,66 & 69,7 & 74,68 & 76,95 & 73,78 \\
\hline 2 & Kremboong & 69,58 & 84,29 & 94,27 & 82,71 & 92,67 & 88,7 & 90,41 & 90,59 & 75,75 & 76,16 & 77,55 & 76,49 \\
\hline 3 & Gempolkrep & 96,64 & 93,24 & 93,79 & 94,56 & 99,72 & 100,8 & 96,73 & 99,08 & 70,19 & 71,48 & 79,05 & 73,57 \\
\hline 4 & Djombang Br & 91,80 & 94,04 & 95,57 & 93,80 & 97,36 & 96,96 & tad & 97,16 & 72,18 & 81,84 & 75,38 & 76,47 \\
\hline 5 & Tjoekir & 91,32 & 90,45 & 94,35 & 92,04 & 97,8 & 100 & $\operatorname{tad}$ & 98,90 & 79,5 & 80,57 & 76,75 & 78,94 \\
\hline 6 & Pesantren & 88,44 & 94,71 & 95,41 & 92,85 & 93,6 & 95,39 & 100,8 & 96,60 & 76,98 & 78,21 & 76,55 & 77,25 \\
\hline 7 & Meritjan & 97,29 & 96,58 & 91,82 & 95,23 & 92,4 & tad & 98,37 & 95,39 & 71,24 & 73,82 & 74,34 & 73,13 \\
\hline 8 & Ngadiredjo & 95,39 & 96,50 & 94,91 & 95,60 & 100,8 & 99,49 & 100,5 & 100,26 & 75,73 & 81,14 & 79,17 & 78,68 \\
\hline 9 & Mj Panggoong & 92,64 & 95,24 & 91,57 & 93,15 & 91,82 & 89,62 & 91,33 & 90,92 & 76,86 & 78,41 & 77,76 & 77,68 \\
\hline \multicolumn{14}{|c|}{ E PTPN XI } \\
\hline 1 & Sudhono & 48 & 86,90 & 79,99 & 82,79 & 88,35 & 91,49 & 96,78 & 92,21 & 74,03 & 71,34 & 80,81 & $\begin{array}{l}75,39 \\
\end{array}$ \\
\hline 2 & Redjosarie & 92,39 & 91,26 & 78,27 & 87,31 & 95,01 & 95,3 & 96,78 & 95,70 & 54,76 & 74,7 & 56,44 & 61,97 \\
\hline 3 & Pagot & 30 & 98,73 & 90,28 & 95,77 & 83,74 & 90,5 & 90,64 & 88,29 & 80,34 & 81,88 & 86,99 & 83,07 \\
\hline 4 & Kanigoro & 90,72 & 98,59 & 83,73 & 91,01 & 90,07 & 98,99 & 100,3 & 96,45 & 75,17 & 73,32 & 76,45 & 74,98 \\
\hline 5 & Kedawoeng & 86,33 & 94,96 & 83,74 & 88,34 & 89,29 & 89,66 & 98,8 & 92,58 & 69,54 & 77,04 & 80,5 & 75,69 \\
\hline 6 & Padjarakan & 88,20 & 80,91 & 95,50 & 88,20 & 79,25 & 88,85 & 99,93 & 89,34 & 69,08 & 79,78 & 75,08 & 74,65 \\
\hline 7 & Pandjie & tad & $\operatorname{tad}$ & 96,83 & 96,83 & 91,72 & 97,58 & 100,5 & 96,60 & 76,63 & 83,47 & 79,64 & 79,91 \\
\hline 8 & Olean & 85,12 & 93,01 & 92,33 & 90,15 & 85,61 & 95,21 & 88,62 & 89,81 & 67,7 & 74,04 & 75,02 & 72,25 \\
\hline 9 & Assemk & 75 & 80,14 & 85,51 & 83,80 & 87,84 & 91,43 & 96,32 & 91,86 & 77,17 & 77,74 & 78,12 & 77,68 \\
\hline 10 & Semboro & 79,39 & 76,59 & 81,95 & 79,31 & 79,3 & 79,44 & 93,04 & 83,93 & 77,75 & 76,4 & 85,87 & 80,01 \\
\hline \multicolumn{14}{|c|}{ F PTPN XIV } \\
\hline 1 & Camming & 17 & 84 & 72,27 & 3,42 & 03 & 1,04 & 78,63 & 82,23 & 66,48 & 63,49 & 75,07 & 68,35 \\
\hline 2 & Bone & 50,84 & 65,22 & 70,77 & 62,27 & 90,74 & 62,85 & 60,31 & 71,30 & tad & 36,22 & 73,51 & 54,87 \\
\hline $\mathrm{G}$ & PT RNI I & & & & & & & & & & & & \\
\hline 1 & Krebet Baru & 14 & 96,53 & 89,78 & 92,48 & 92,82 & 94,38 & 98,18 & 95,13 & 75,11 & 77,35 & 79,69 & 77,38 \\
\hline 2 & Krebet Baru 2 & 92,32 & 92,71 & 92,79 & 92,61 & 93,78 & 93,96 & 97,56 & 95,10 & 72,91 & 76,71 & 82,52 & 77,38 \\
\hline 3 & Redj Agung Br & 89,28 & 93,84 & 91,72 & 91,61 & 96,7 & 94,43 & 92,9 & 94,68 & 77,13 & 78,28 & 77,89 & 77,77 \\
\hline \multicolumn{14}{|c|}{ H PT RNIII } \\
\hline 1 & Krg Suwung & 78,66 & 89,48 & 97,41 & 88,52 & 97,82 & 86,87 & 94,22 & 92,97 & 76,64 & 76,5 & 77,53 & 76,89 \\
\hline 2 & Tersana Baru & 63,57 & 83,05 & 93,79 & 80,14 & 87,2 & 90,63 & 88,88 & 88,90 & 72,9 & 74,62 & 75,77 & 74,43 \\
\hline 3 & Sindang Laut & 80,65 & 97,97 & 96,19 & 91,60 & 71,07 & 76,06 & 73,26 & 73,46 & 75,37 & 76,04 & 76,27 & 75,89 \\
\hline 4 & Subang & 86,55 & 90,54 & 92,67 & 89,92 & 93,51 & 96,9 & 95,3 & 95,24 & 70,83 & 73,36 & 75,92 & 73,37 \\
\hline$\overline{\mathrm{REF}}$ & RATA PG BUMN & 83,23 & 87,77 & 88,29 & 86,43 & 90,70 & 90,99 & 92,5 & 91,39 & 75,18 & 76,70 & 79,19 & 77,02 \\
\hline
\end{tabular}

Sumber: hasil pengolahan dari data kompilasi Kementerian Perindustrian [25]

Keterangan: tad: tidak ada data

PG sampel yang rata-rata performance-nya selama tiga tahun pengamatan mampu membuat capaian kelas dunia. PG tersebut menyebar di PTPN VII (1 PG atau 50\%), PTPN IX (2 PG atau 28\%), PTPN X (7 PG atau 78\%), PTPN XI (2 PG atau 20\%), dan RNI I (2 PG atau 67\%), dan RNI II (1 PG atau 25\%). Performance rata-rata untuk seluruh PG dalam obyek studi selama tiga tahun data menunjukkan kecenderungan meningkat, walaupun rata-ratanya masih di bawah best practice, yaitu 91,48\%. Selama tiga tahun data (2010-2012), 10 PG BUMN obyek studi yang rata-rata tingkat performance-nya paling rendah secara berturutturut (mulai dari yang terrendah) adalah: (1) Bone, (2) Sindang Laut, (3) Sragi, (4) Camming, (5) Modjo, (6) Semboro, (7) Pagottan, (8) Cinta Manis, (9) Tersana Baru, dan (10) Sei Semayang. PG sampel yang tingkat Performance-nya selama tiga tahun pengamatan menurun secara konsisten adalah PG Sumberhardjo (PTPN IX), PG Camming, PG Bone (PTPN XIV), dan PG Redjoagung Baru (RNI I). Sementara yang performance-nya meningkat secara konsisten ada $8 \mathrm{PG}$, yang tersebar pada PTPN IX, X, XI, RNI I. 


\section{Quality}

Quality merupakan suatu rasio yang menggambarkan kemampuan peralatan dalam menghasilkan produk yang sesuai dengan standar, yang nilainya merupakan persentase dari jumlah produk yang baik (good count) terhadap jumlah total produk yang diproses. Pada pabrik gula, potensi jumlah gula terindikasi dari kandungan pol tebu, yaitu angka yang menunjukkan kadar gula (sukrosa) yang terdapat dalam nira tebu. Jika proses berlangsung sempurna, jumlah gula kristal putih yang dihasilkan seharusnya merupakan hasil perkalian antara jumlah tebu digiling dengan pol tebu. Dalam prakteknya, proses konversi dari tebu menjadi gula kristal tidak mungkin terjadi secara sempurna, karena terjadi kehilangan gula pada berbagai tahapan proses, yaitu terikut dalam ampas tebu (pol ampas), limbah padat/blotong (pol blotong), dan molase (pol tetes), serta sebagian menjadi gula konversi. Rasio yang menunjukkan kemampuan mesin dan alat pabrik untuk mengkoversi potensi jumlah gula (pol tebu x tebu digiling) menjadi gula produk (gula kristal putih) disebut oleh International Society of Sugar Cane Technologists (ISSCT) sebagai overall recovery (OR), dan dalam konsep OEE di sini dianggap sebagai tingkat Quality. Selisih antara potensi jumlah gula dengan realisasi gula yang dihasilkan merupakan kehilangan dalam proses, yang dianggap sama dengan quality losses. Best practice Quality (kelas dunia) untuk industri manufaktur yang prosesnya bekerja secara kontinyu, menurut referensi adalah 99,9\% (Dal [22]; Wauters dan Mathot [23]). Namun demikian konsep Quality ini kurang relevan untuk diterapkan pada pabrik gula yang lebih dekat kepada industri proses. Menurut Subiyono [26], best practice untuk overall recovery pada industri gula kristal putih tingkat dunia adalah sekitar 91\%. Berdasarkan Tabel 6 dapat disampaikan:

Mengacu kepada referensi best practice overall recovery untuk industri gula kristal putih tingkat dunia yang nilainya $91 \%$, maka tidak ada di antara PG sampel yang pernah mencapai prestasi ini selama periode 3 tahun pengamatan. Quality ratarata untuk seluruh $\mathrm{PG}$ dalam obyek studi selama tiga tahun data menunjukkan kecenderungan meningkat, walaupun rata-ratanya masih jauh di bawah best practice, yaitu $76,79 \%$. Selama tiga tahun data (2010-2012), 10 PG BUMN obyek studi yang rata-rata tingkat Quality-nya paling rendah secara berturut-turut (mulai dari yang terrendah) adalah: (1) Bone, (2) Redjosarie, (3) Camming, (4) Cinta Manis, (5) Olean, (6) Meritjan, (7) Subang, (8) Gempol Krep, (9) Toelangan, dan (10) Tersana Baru. Selama tiga tahun data, tidak ada PG sampel yang tingkat Quality-nya menurun secara konsisten, sedangkan yang naik secara konsisten ada $14 \mathrm{PG}$, yang tersebar di PTPN IX (3 PG), PTPN X (4 PG), PTPN XI (3 PG), RNI I (2 PG), dan RNI II (2 PG).

\section{Overall Equipment Effectiveness (OEE)}

Best practice OEE (kelas dunia) untuk industri manufaktur yang prosesnya bekerja secara kontinyu, menurut referensi adalah 85\% (Dal [22]; Wauters dan Mathot [23]). Angka ini sejalan dengan referensi yang disampaikan oleh Bhagat [27], bahwa rata-rata overall plant eficiency pada pabrik gula di negara-negara terkemuka adalah sekitar 85\%. Hasil perhitungan OEE pada 39 PG BUMN selama tiga tahun pengamatan ditunjukkan pada Tabel 5.

Berdasarkan Tabel 5 dapat disampaikan:

Mengacu kepada best practice OEE pada industri manufaktur yang nilainya $85 \%$, maka tidak ada di antara PG obyek studi yang pernah mencapai prestasi ini selama periode 3 tahun pengamatan. Jika acuan untuk elemen Quality menggunakan referensi dari Subiyono [26] yaitu 91\%, maka best practice untuk OEE nilainya menjadi $77,43 \%$, dan ini berarti hanya PG Ngadiredjo pada tahun 2011 (PTPN X) dan PG Panjie pada tahun 2012 (PTPN $\mathrm{XI}$ yang pernah mencapainya. OEE rata-rata untuk seluruh PG dalam obyek studi selama tiga tahun data menunjukkan kecenderungan meningkat, walaupun rata-ratanya masih jauh di bawah best practice, yaitu $61,28 \%$. Selama tiga tahun data (2010-2012), 10 PG BUMN obyek studi yang ratarata tingkat OEE-nya paling rendah secara berturut-turut (mulai dari yang terrendah) adalah: (1) Bone, (2) Camming, (3) Cinta Manis, (4) Sragi, 5) Sindang Laut, (6) Redjosarie, (7) Tersana Baru, (8) Semboro, (9) sei Semayang, dan (10) Kremboong;. Selama tiga tahun data, tidak ada PG sampel yang tingkat OEE-nya menurun secara konsisten, sebaliknya yang naik secara konsisten ada $14 \mathrm{PG}$, yang tersebar di PTPN IX (3 PG), PTPN X (4 PG), PTPN XI (3 PG), RNI I (2 PG), dan RNI II (2 PG).

\section{Pendekatan Revitalisasi}

Dalam melakukan pembinaan PG BUMN, pemerintah selaku pemegang saham dari seluruh PG BUMN dituntut untuk mampu bersikap netral. Dalam hal demikian, pilihan pendekatan untuk pembinaan $\mathrm{PG}$ dapat ditempuh melalui skema penyehatan (bukan insentif). Pemilihan PG yang mesin/peralatannya perlu direstrukturisasi (lanjutan) dapat ditempuh dengan melihat PG yang efektifitas permesinan/peralatannya paling buruk. Tentunya dengan catatan bahwa PG yang bersangkutan masih didukung dengan pasokan tebu yang memadai. 
Tabel 5. Overall Equipment Effectiveness (OEE) PG BUMN tahun 2010-2012

\begin{tabular}{|c|c|c|c|c|c|}
\hline \multirow[t]{2}{*}{ No } & \multirow{2}{*}{$\begin{array}{c}\text { Perusahaan/pabrik } \\
\text { Gula }\end{array}$} & \multicolumn{4}{|c|}{$\begin{array}{c}\text { Overall Equipment Effectiveness/ } \\
\text { OEE }(\%)\end{array}$} \\
\hline & & 2010 & 2011 & 2012 & Rerata \\
\hline \multicolumn{6}{|c|}{ A PTPN II } \\
\hline 1 & Sei Semayang & Tad & 54,12 & 56,79 & 55,46 \\
\hline 2 & Kuala Madu & 67,08 & 58,46 & 67,08 & 64,21 \\
\hline $\mathrm{B}$ & PTPN VII & & & & \\
\hline 1 & Bungamayang & 57,06 & 70,87 & 62,77 & 63,57 \\
\hline 2 & Cinta Manis & 48,34 & 48,85 & tad & 48,60 \\
\hline \multicolumn{6}{|c|}{ C PTPN IX } \\
\hline 1 & Gondang Baru & 64,63 & 66,87 & 68,91 & 66,81 \\
\hline 2 & Tasikmadu & 71,61 & 72,44 & 68,14 & 70,73 \\
\hline 3 & Modjo & 50,33 & 60,62 & 66,59 & 59,18 \\
\hline 4 & Sragi & 43,12 & 51,21 & 56,07 & 50,14 \\
\hline 5 & Sumberharjo & 70,04 & 59,84 & 66,83 & 65,57 \\
\hline 6 & Pangka & 57,43 & 74,59 & 74,51 & 68,84 \\
\hline 7 & Jati Barang & 48,99 & 59,61 & 66,51 & 58,37 \\
\hline \multicolumn{6}{|c|}{ PTPN X } \\
\hline 1 & Toelangan & 60,52 & 67,88 & 67,86 & 65,42 \\
\hline 2 & Kremboong & 48,85 & 56,94 & 66,09 & 57,29 \\
\hline 3 & Gempolkrep & 67,64 & 67,18 & 71,72 & 68,85 \\
\hline 4 & Djombang Baru & 64,51 & 74,62 & tad & 69,57 \\
\hline 5 & Tjoekir & 71,00 & 72,88 & tad & 71,94 \\
\hline 6 & Pesantren Baru & 63,72 & 70,66 & 73,62 & 69,33 \\
\hline 7 & Meritjan & 64,04 & tad & 67,15 & 65,60 \\
\hline 8 & Ngadiredjo & 72,82 & 77,90 & 75,52 & 75,41 \\
\hline 9 & Modjo Panggoong & 65,38 & 66,93 & 65,03 & 65,78 \\
\hline \multicolumn{6}{|c|}{ PTPN XI } \\
\hline 1 & Sudhono & 53,29 & 56,72 & 62,55 & 57,52 \\
\hline 2 & Redjosarie & 48,07 & 64,97 & 42,75 & 51,93 \\
\hline 3 & Pagottan & 66,13 & 73,16 & 71,18 & 70,16 \\
\hline 4 & Kanigoro & 61,42 & 71,56 & 64,20 & 65,73 \\
\hline 5 & Kedawoeng & 53,60 & 65,59 & 66,60 & 61,93 \\
\hline 6 & Padjarakan & 48,29 & 57,35 & 71,65 & 59,10 \\
\hline 7 & Pandjie & tad & tad & 77,50 & 77,50 \\
\hline 8 & Olean & 49,33 & 65,56 & 61,38 & 58,76 \\
\hline 9 & Assembagoes & 58,13 & 56,96 & 64,34 & 59,81 \\
\hline 10 & Semboro & 48,95 & 46,48 & 65,47 & 53,63 \\
\hline \multicolumn{6}{|c|}{ F PTPN XIV } \\
\hline 1 & Camming & 30,76 & 33,36 & 42,66 & 35,59 \\
\hline 2 & Bone & tad & 14,85 & 31,37 & 23,11 \\
\hline \multicolumn{6}{|c|}{ PT RNI I } \\
\hline 1 & Krebet Baru 1 & 63,54 & 70,47 & 70,24 & 68,08 \\
\hline 2 & Krebet Baru 2 & 63,12 & 66,82 & 74,71 & 68,22 \\
\hline 3 & Redjo Agung Baru & 66,59 & 69,36 & 66,37 & 67,44 \\
\hline \multicolumn{6}{|c|}{ H PT RNI II } \\
\hline 1 & Karang Suwung & 58,97 & 59,47 & 71,15 & 63,20 \\
\hline 2 & Tersana Baru & 40,41 & 56,16 & 63,16 & 53,25 \\
\hline 3 & Sindang Laut & 43,20 & 56,66 & 53,74 & 51,20 \\
\hline 4 & Subang & 57,32 & 64,36 & 67,05 & 62,91 \\
\hline & ERATA PG BUMN & 57,45 & 61,69 & 64,70 & 61,28 \\
\hline
\end{tabular}

Dalam konsep OEE, efektivitas peralatan pabrik dapat dilihat dari nilai elemen Availability, Performance, dan Quality. Efektivitas peralatan pabrik terburuk yang dievaluasi dari data pada Tabel 4 berdasarkan 10 pabrik dengan nilai terkecil untuk setiap elemen OEE, menghasilkan 19 PG yang perlu mendapat prioritas untuk direvitalisasi. Ke-19 PG tersebut adalah: Bone, Camming, Cinta Manis, Sragi, Tersana Baru, Semboro, Sindang Laut, Redjosarie, Sei Semayang, Jati Barang, Kremboong, Modjo, Pagottan, Olean, Subang, Redjosarie, Gempolkrep, Meritjan, dan Toelangan. Namun demikian rencana aksi revitalisasi terhadap ke-19 PG ini perlu diperkaya dengan pemahaman:

Availability sangat ditentukan oleh jam berhenti giling (down time), dimana penyebabnya bukan semata karena faktor mesin/alat (faktor dalam pabrik), tetapi juga karena sebab eksternal khususnya pasokan tebu ke pabrik. Revitalisasi mesin/alat memerlukan informasi yang lebih spesifik khususnya terkait data down time karena sebab mesin/alat pabrik (faktor dalam). Terpisahnya kepemilikan dan manajemen antara kebun dan pabrik sebagai konsekuensi atas keluarnya Kepres nomor 14 tahun 1975, kewenangan pabrik atas pasokan tebu sangat terbatas, sehingga berdampak kepada kurang lancarnya pasokan tebu ke pabrik. Upaya revitalisasi mesin/alat yang berorientasi kepada peningkatan nilai Availability perlu diimbangi dengan perbaikan koordinasi antara pabrik dan kebun khususnya dalam hal manajemen tebang angkut, agar pasokan tebu ke pabrik tidak terganggu.

Performance yang rendah dapat terjadi karena mesin/alat tidak berfungsi sesuai rencana (malfunction), atau karena rancangan mesin/alat yang kapasitasnya kurang seimbang sehingga kecepatan alat harus disesuaikan pada tingkatan yang tidak masimal. Program revitalisasi mesin/alat pabrik ke depan perlu dilengkapi dengan informasi tentang OEE per stasiun alat agar pemilihan jenis mesin/alat yang akan direvitalisasi tepat sasaran dan mampu memberikan nilai tambah maksimal.

Quality dalam industri gula kristal putih nilainya sangat dipengaruhi oleh efektifitas kerja mesin/alat dan teknologi proses, khususnya dalam pengendalian losses. Konversi nira tebu menjadi gula kristal putih merupakan proses fisika, kimia, dan biologi, yang efektifitasnya banyak dipengaruhi oleh kemampuan mengendalikan kondisi proses. Kontrol pengendalian proses pada sebagian besar PG BUMN saat ini masih menggunakan cara manual yang akurasinya sukar diandalkan. Adanya kelengkapan instrumentasi sebagai alat kontrol kondisi proses yang andal tentunya akan membantu kinerja PG khususnya dalam meningkatkan nilai Quality. Alat ini perlu menjadi perhatian dalam pelaksanaan program revitalisasi mesin/alat pabrik gula ke depan.

\section{Simpulan}

Program revitalisasi mesin/alat pabrik gula BUMN yang dijalankan pemerintah pada tahun 2010-2012 secara umum memberikan dampak positif, dengan indikasi adanya peningkatan setiap elemen OEE dari rata-rata $P G$. Namun demikian status OEE dari rata-rata $\mathrm{PG}$ masih jauh dari kondisi ideal. 
Kondisi mesin dan peralatan pabrik gula BUMN secara umum lemah pada fungsi efisiensi proses (quality: 76,79\%) dan kesiapan alat (availability: $86,52 \%$ ), tetapi relatif baik pada fungsi kecepatan giling (performance: 91,48\%). Penilaian kumulatif berbasis elemen OEE dari 39 PG BUMN mengindikasikan adanya 19 PG BUMN yang efisiensi mesin/alat-nya masih kurang baik.

Perlu dilakukan perhitungan OEE lanjutan (per stasiun alat) terhadap $19 \mathrm{PG}$ dengan elemen OEE terendah, agar jenis mesin/alat yang perlu distrukturisasi untuk masing-masing PG dapat diidentifikasi secara lebih akurat.

\section{Daftar Pustaka}

1. Sewoko, C., Kebijakan Revitalisasi Industri Gula Nasional, Bahan Forum Group Discusion di Badan Pengkajian dan Penerapan Teknologi (BPPT) Jakarta, 19 Oktober 2010, Asosiasi Gula Indonesia, 2012.

2. Neraca, 03/12/2013, Pemerintah Langgar 8 Kebijakan Pergulaan Nasional, (http://www.neraca. co.id).

3. Kepres nomor 57 tahun 2004 tentang Penetapan Gula Sebagai Barang dalam Pengawasan.

4. Peraturan Presiden No. 5 Tahun 2010 tentang Rencana Pembangunan Jangka Menengah Nasional (RPJMN).

5. Peraturan Menteri Perdagangan Nomor 18/MDAG/PER/4/2007 tentang Ketentuan Impor Gula.

6. Ditjen Perkebunan Kementerian Pertanian, Buku Statistik Perkebunan Tahun 2008-2012. (www. deptan.go.id; last update 10 Februari 2014).

7. Kementerian BUMN, Data Produksi PTPN \& RNI 2010 - 2014. Bahan Presentasi, 2013.

8. Pusat Data dan Sistem Informasi Pertanian, Kementerian Pertanian, Kinerja Perdagangan Komoditas Pertanian, 4(1), 2013, pp. 85-103.

9. Kementerian Perindustrian, Pelaksanaan Program Revitalisasi Industri Gula 2010-2014. Bahan Presentasi, 2013.

10. Nakajima, S., Introduction to TPM, Productivity Press, Cambridge, MA., 1988.

11. Huang, S. H., Dismukes, J. P, Mousalam, A., Razzak, R. B., and Robinson, D. E, Manufacturing Productivity Improvement Using Effectiveness Metrics and Simulation Analysis, International Journal of Production Research, 41(3), 2003, pp.513-527.

12. Williamson, R. M., Using Overall Equipment Effectiveness: The Metric and the Measures, Strategic Work Systems, Inc, Columbus, 2006. Available online at: (http://www.swspitcrew. com).
13. Robinson dan Ginder, Implementing TPM: The North American Experience. Productivity Press, Portland, USA. (eBook), 1995.

14. Sherwin, D., A Review of Overall Models for Maintenance Management, Journal of Quality in Maintenance Engineering, 6(3), 2000, pp. 138164.

15. Nachiappan, R.M. and Anantharam, N., Evaluation of Overall Line Effectiveness (OLE) in a Continuous Product Line Manufacturing System, Journal of Manufacturing Technology Management, 17(7), 2006, pp. 987-1008.

16. Braglia, M., Frosolini, M. and Zammori, F., Overall Equipment Effectiveness of a Manufacturing Line (OEEML): An Integrated Approach to Assess Systems Performance, Journal of Manufacturing Technology Management, 20(1), 2009, pp. 8-29.

17. Oechser R., Pfeffer M., Pftzner L., Binder H., Muller E., Vonderstrass T., From Overall Equipment Effectiveness to Overall Fab Effectivenes s (OFE), Material Science in Semiconductor Processing, 5, Issue 4-5, 2003, pp 333-339.

18. Rahmad, P., dan Slamet W., Penerapan Overall Equipment Effectiveness (OEE) Dalam Implementasi Total Productive Maintenance (TPM) (Studi Kasus di Pabrik Gula PT 'Y'). Jurnal Rekayasa Mesin, 3(3), 2012, pp. 431-437.

19. Mulyati, D., Analisis Efektivitas Peralatan Produksi Pada PT. Bahari Dwikencana Lestari Kabupaten Aceh Tamiang, Jurusan Teknik Manajemen Industri, Fakultas Teknik Universitas Serambi Mekkah, Banda Aceh, 2012.

20. Fitriadi, R., dan Kuncoro, B. G. Analisa Perbaikan Mesin CNC MA-1 dengan Menggunakan Indikator Kinerja Overall Equipment Effectiveness (OEE). Prosiding SNST ke-4 Tahun 2013 Fakultas Teknik Universitas Wahid Hasyim Semarang, 2013.

21. PTPN X, Angka-angka Pengawasan Pabrik Gula. Bahan Inhouse Training Mandor-mandor. Tretes, 11-14 Januari 2011.

22. Dal, B., Tugwell, P., and Greatbanks, R., Overall Equipment Effectiveness as a Measure of Operational Improvement - A Practical Analysis, International Journal of Operations \& Production Management, 20 (12), 2000, pp. 1488-1502.

23. Wauters, F., and Mathot, J., Overall Equipment Effectiveness, A Whitepaper, 2002, (http://www05.abb.com/global).

24. EXOR/DataVisor Marquees, The Complete Guide to Simple OEE: Overall Equipment Effectiveness $(O E E)$, Cincinnati, Ohio, E-document, Downloaded: January 13, 2014. (www.exor-rd.com).

25. Kementerian Perindustrian, Laporan Kinerja Produksi Pabrik Gula. Program Revitalisasi Industri Gula Melalui Restrukturisasi Mesin 
dan/atau Peralatan Pabrik Gula. Kerjasama dengan Surveyor Indonesia, 2013.

26. Subiyono, Succes Story PTPN X Tahun 2011, Bahan Konggres IKAGI Februri 2012 di Surabaya, 2012.
27. Bhagat, J. J., National Plan for Improving Efficiency in Indonesian Sugar Industry-Field \& Factory, STM Projects Limited, New Delhi. India, 2012. 